\title{
Association of Helicobacter pylori babA2 gene and gastric cancer risk: a meta- analysis
}

Marce-Amara Kpoghomou ${ }^{1,2 \dagger}$, Jinchen Wang ${ }^{1,2 \dagger}$, Tianpei Wang ${ }^{1,2}$ and Guanfu Jin ${ }^{1,2^{*}}$

\begin{abstract}
Background: The association of Helicobacter pylori (H. pylori) babA2 gene with gastric cancer (GC) was reported by several studies, but results were inconsistent. This meta-analysis was performed to investigate the relationship between $H$. pylori babA2 gene and GC risk.

Methods: Case-control studies involving the association between H. pylori babA2 gene and GC risk were systematically identified from PubMed databases. A meta-analysis was used to pool studies and to estimate odds ratios (ORs) with 95\% confidence intervals (Cls) of H. pylori babA2 gene associated with GC risk.

Results: Twenty studies were identified with a total of 1289 GC cases and 1081 controls. H. pylori babA2 gene was associated with an increased risk of GC by 2.05 fold $(95 \% \mathrm{Cl}, 1.30-3.24, P=0.002)$. In subgroup analysis, we found that H. pylori babA2 gene was significantly associated with GC risk in Asian population (OR=2.63, 95\% Cl: 1.36-5.09 $P=0.004)$ but not in South American population $(\mathrm{OR}=1.35,95 \% \mathrm{Cl}: 0.69-2.64, P=0.379)$.

Conclusions: This meta-analysis indicates that $H$. pylori babA2 gene may be associated with increased risk of GC, especially in Asian population.
\end{abstract}

Keywords: Helicobacter pylori, babA2 gene, Gastric cancer, Meta-analysis

\section{Background}

Gastric Cancer (GC) is the fifth most common cancer and the third leading cause of mortality worldwide [1-3], with approximately $42.5 \%$ of all cases diagnosed in China $[4,5]$. About 1 million incident cases of GC are annually projected, with the majority observed in Eastern Asia, Latin America and Eastern Europe [5]. In 2015, GC was the second most common cancer with about 6,791,000 new cases in China [4]. Genetic and environment factors are

\footnotetext{
* Correspondence: guangfujin@njmu.edu.cn
${ }^{+}$Marce-Amara Kpoghomou and Jinchen Wang contributed equally to this

* Correspondence: guangfujin@njmu.edu.cn
${ }^{+}$Marce-Amara Kpoghomou and Jinchen Wang contributed equally to this work.

'Department of Epidemiology, Center for Global Health, School of Public Health, Nanjing Medical University, Nanjing 211166, China

${ }^{2}$ Jiangsu Key Lab of Cancer Biomarkers, Prevention and Treatment, Collaborative Innovation Center for Cancer Medicine, Nanjing Medical University, Nanjing 211166, China
}

involved in GC development. H. pylori infection, cigarette smoking, low intake of fresh vegetables and fruits and salty foods are main risk factors of GC [6].

Helicobacter pylori (H. pylori) infection is the most common human infections inhabiting in the stomach. It is a gram-negative bacterium, which has epigenetic effects on gastric epithelial cells and indirect inflammatory response on the gastric mucosa [7]. Some studies showed that $H$. pylori alone or associated gene were strongly associated with gastric cancer risk [8-10]. According to the International Agency for Research on Cancer, $H$. pylori was defined as a class I carcinogen [11]. However, only a small fraction of infected patients develop severe diseases [12]. H. pylori is well distinguished to have a high level of genetic variations allowing it to be adapted to the host gastric epithelium [13].

(c) The Author(s). 2020 Open Access This article is licensed under a Creative Commons Attribution 4.0 International License, which permits use, sharing, adaptation, distribution and reproduction in any medium or format, as long as you give appropriate credit to the original author(s) and the source, provide a link to the Creative Commons licence, and indicate if changes were made. The images or other third party material in this article are included in the article's Creative Commons licence, unless indicated otherwise in a credit line to the material. If material is not included in the article's Creative Commons licence and your intended use is not permitted by statutory regulation or exceeds the permitted use, you will need to obtain permission directly from the copyright holder. To view a copy of this licence, visit http://creativecommons.org/licenses/by/4.0/ The Creative Commons Public Domain Dedication waiver (http://creativecommons.org/publicdomain/zero/1.0/) applies to the data made available in this article, unless otherwise stated in a credit line to the data. 
It is well described that different strains of $H$. pylori showed different degrees of virulence [14-16]. H. pylori strains harboring the cytotoxin-associated antigen ( $\operatorname{cag} A)$ and the vacuolating toxin $\mathrm{A}(\mathrm{vacA})$ have been considered as risk factors for GC $[15,17,18]$. The OipA, one of porin proteins associated with severe neutrophil infiltration in IL-8 induction and gastric colonization [19], was also associated with GC risk [20-22].

The blood-group antigen-binding adhesin ( $b a b A)$ encoded by $b a b A 2$ gene is a major adhesin on the outer membrane of H. pylori. BabA2 is characterized to be an active gene in the binding activity of Lewis-b blood group antigen on gastric epithelium and host cell and determine $H$. pylori colonization density [23, 24]. The sequence of the three $b a b A$ gene alleles have been identified (babA1, babA2 and $b a b B$ ), but only the babA2 is involve $\mathrm{d}$ in Lewis-b binding activity. To date, several studies have evaluated the effect of $H$. pylori babA2 gene on risk of GC [19, 25-42], but the results are conflicting possibly due to small sample size of single studies. In the present study, we conducted a meta-analysis to assess the association between $H$. pylori babA2 gene and GC risk based on published cases-control studies.

\section{Methods \\ Search strategies}

All relevant studies were identified from PubMed databases. The search strategy included the terms ("babA2" OR "antigen-binding adhesion gene") AND ("Helicobacter pylori" OR "H. pylori infection") AND ("genotype" OR "polymorphism") AND ("gastric cancer" OR "stomach cancer") in any text field of the database. In addition, we also collected additional studies from references of original and review articles.

\section{Inclusion and exclusion criteria}

Inclusion criteria to select studies for this meta-analysis were as follows: (1) study describing the relationship between $H$. pylori babA2 gene and GC, (2) studies that provided babA2 positive frequencies, (3) studies published in English with full text available. Exclusion criteria were as follow: (1) insufficient data to calculate

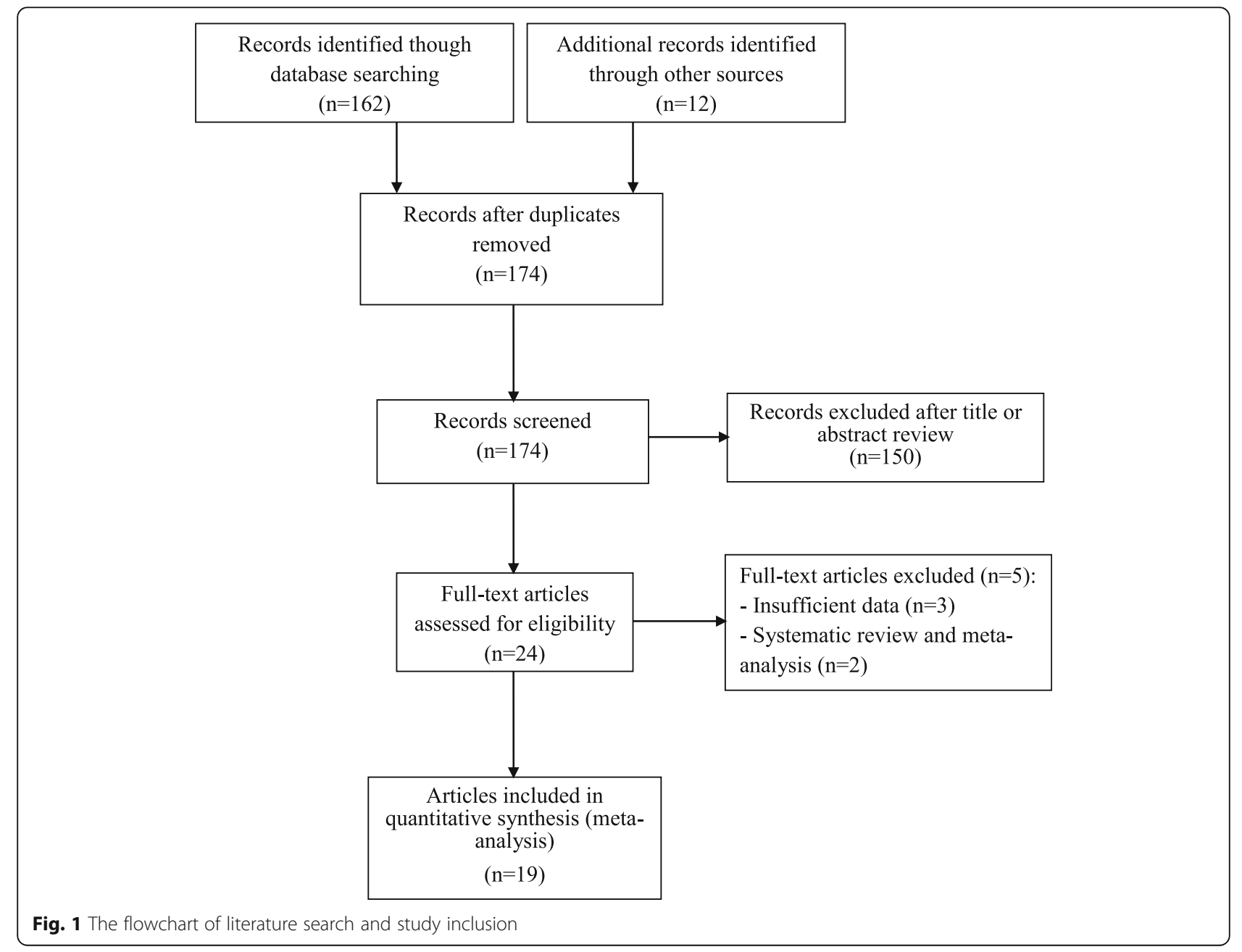


Table 1 Characteristics of included studies

\begin{tabular}{|c|c|c|c|c|c|c|c|}
\hline First Author & Year & Country & Ethnicity & Control & Sample Size (case/control) & OR $(95 \% \mathrm{Cl})$ & Quality Assessment \\
\hline Gerhard & 1999 & Germany & European & Gastritis & $39 / 23$ & $3.31(1.07-10.17)$ & 5 \\
\hline Mizushima & 2001 & Japan & Asian & NUD & $70 / 12$ & $2.12(0.58-7.68)$ & 5 \\
\hline Yamaoka & 2002 & United States & North American & Gastritis & $47 / 23$ & $0.74(0.27-2.02)$ & 5 \\
\hline Yamaoka & 2002 & Colombia & South American & Gastritis & $62 / 19$ & $2.08(0.72-6.00)$ & 5 \\
\hline Oliveira & 2003 & Brazil & South American & Gastritis & $53 / 75$ & $2.73(1.32-5.67)$ & 7 \\
\hline Han & 2004 & Shanghai & Asian & Chronic gastritis & $40 / 24$ & $0.71(0.25-2.08)$ & 6 \\
\hline Lee & 2006 & South korea & Asian & Routine gastoscopy & $98 / 136$ & $3.98(1.94-8.15)$ & 7 \\
\hline Chomvarin & 2007 & Thailand & Asian & NUG & $72 / 6$ & $1.32(0.14-12.13)$ & 6 \\
\hline Zhang & 2008 & China & Asian & Gastritis & $143 / 69$ & $1.07(0.59-1.94)$ & 6 \\
\hline Erzin & 2008 & Turkey & Asian & NUD & $36 / 34$ & $31.07(8.22-117.52)$ & 6 \\
\hline Bartchewsky & 2009 & Brazil & South American & Gastritis & $142 / 38$ & $0.96(0.44-2.12)$ & 6 \\
\hline Safaei & 2010 & Iran & Asian & CAG & $38 / 16$ & $1.87(0.35-9.96)$ & 5 \\
\hline Mattar & 2010 & Brazil & South American & Gastritis & $36 / 32$ & $0.38(0.14-1.02)$ & 5 \\
\hline Saxena & 2011 & India & Asian & NUD & $45 / 123$ & $1.12(0.49-2.57)$ & 7 \\
\hline Abadi & 2011 & Iran & Asian & NUD & $55 / 50$ & $53.65(11.67-246.69)$ & 5 \\
\hline Mottaghi & 2014 & Iran & Asian & Chronic gastritis & $60 / 12$ & $0.65(0.18-2.31)$ & 6 \\
\hline Abdi & 2016 & Iran & Asian & NAG & $22 / 61$ & $2.81(1.02-7.74)$ & 6 \\
\hline Roman-Roman & 2017 & Mexico & South American & Chronic gastritis & $109 / 282$ & $1.93(0.83-4.50)$ & 7 \\
\hline Heidari & 2017 & Iran & Asian & Gastritis & $32 / 22$ & $1.12(0.35-3.57)$ & 5 \\
\hline Bartpho & 2020 & Thailand & Asian & Chronic gastritis & $90 / 24$ & 7.38 (2.64-20.09) & 6 \\
\hline
\end{tabular}

NUD Non-ulcer Dyspepsia, NAG Non-atrophic gastritis, CAG Chronic active gastritis

OR and 95\% CI, (2) vivo or experimental studies, and (3) meta-analysis or review studies.

\section{Data extraction}

Data were extracted from each study independently by two investigators and contradictions between them were discussed to obtain agreement. The following information's were collected: first author's name, year of publication, country, ethnicity, sample size, type of study, source of sample, study quality assessment, babA2 positive frequencies, OR estimation and 95\% CI for the association between $H$. pylori babA2 gene and GC.

\section{Quality score assessment}

Quality score of each included study was assessed by the same two authors independently using the NewcastleOttawa Quality Assessment Scale (NOS) for casecontrol studies [43]. The NOS is a validated quality assessment for case-control studies with three parameters for quality: selection, comparability and exposure. The maximum score of each parameter is 4 for selection, 2 for comparability and 3 for exposure.

\section{Statistical analysis}

The pooled ORs with $95 \%$ CIs were used to indicate the effect of $H$. pylori babA2 gene effect on GC risk. $\chi^{2}$ base on $Q$ test and $I^{2}$ statistics were used to evaluate the statistical heterogeneity among included studies. The fixedeffects model was used when there was no significant heterogeneity $\left(P \geq 0.10\right.$ and $\left.I^{2} \leq 50 \%\right)$ [44, 45] between studies, otherwise the random effect model was applied to provide more conservative estimates [46]. In addition, we performed subgroup analysis by ethnicity and quality score assessment. Ethnicities were divided into Asian, European, South American and North American. Moreover, sensitivity analyses were performed to estimate the effect of each included study on overall effect. We used Begg's test and Egger's test to estimate publication bias [47]. All the statistical analyses were performed using STATA 11.0.

\section{Results}

\section{Characteristics of selected studies}

Literature research strategy is detailed in Fig. 1. There were 174 potentially relevant studies. After title and abstract evaluation, 24 articles with full-text assessment were included when duplicated studies were excluded. After full-text reviewed, a total of 19 eligible articles were included in this meta-analysis, and 5 articles were excluded because of the following reasons: two articles were reviews $[48,49]$, and three articles had insufficient data [50-52]. One article included participants from two countries [19], 
which were considered as two independent studies for subsequent data extraction and meta-analysis. Among 20 studies, 5 were from South American population [19, 26, 32, 34, 40], 13 from Asian population [25, 27-31, 33, 3539, 41], one from North American population [19] and one from European population [42] (Table 1).

\section{Meta-analysis}

There were 20 studies $[19,25-42]$ that investigated the association between $H$. pylori babA2 gene and GC risk. In total, 1289 cases and 1081 controls were included in this meta-analysis (Table 1). The overall proportions of H. pylori babA2 were $39.02 \%(503 / 1289)$ in GC cases and $19.52 \%(211 / 1081)$ in controls. H. pylori babA2 gene was significantly associated with an increased risk of GC $(\mathrm{OR}=2.05,95 \% \mathrm{CI}: 1.30-3.24, P=0.002)$ (Fig. 2). In subgroup analysis, we found significant associations in Asian population $(\mathrm{OR}=2.63,95 \% \mathrm{CI}:$ 1.36-5.09, $P=0.004)$ but not in South American population $(\mathrm{OR}=$ 1.35, 95\%CI: 0.69-2.64, $P=0.379$ ) (Fig. 3).

\section{Heterogeneity analysis and quality assessment}

Heterogeneity analysis showed a significant high heterogeneity among studies $\left(I^{2}=75.6 \%, P<0.001\right)$. In subgroup analysis by ethnicity, heterogeneity was high for Asian $\left(I^{2}=79.5 \%, P<0.001\right)$ but moderate for South American $\left(I^{2}=66.5 \%, P=0.018\right)$. By exploring the potential sources of the heterogeneity, we found that the studies by Erzin et al. [36] and Abadi et al. [30] showed larger effect estimates (OR $=31.07,95 \%$ CI: 8.22-117.52) [36], and $\mathrm{OR}=53.65,95 \% \mathrm{CI}: 11.67-246.69$ [30], respectively), as compared with other studies. According to the Newcastle-Ottawa study quality assessment scale, we found that studies with score of 7 showed a significant association $(\mathrm{OR}=2.27,95 \% \mathrm{CI}: 1.34-3.85)$. However, we didn't find significant association among studies with score of 6 or $5(\mathrm{OR}=2.07,95 \%$ CI: $0.90-4.77$ and $\mathrm{OR}=2.01,95 \%$ CI: 0.79-5.11, respectively) (Figure S1).

\section{Publication bias and sensibility analysis}

Publication bias was evaluated by Begg's and Egger's test. The visual inspection of funnel plot revealed that there

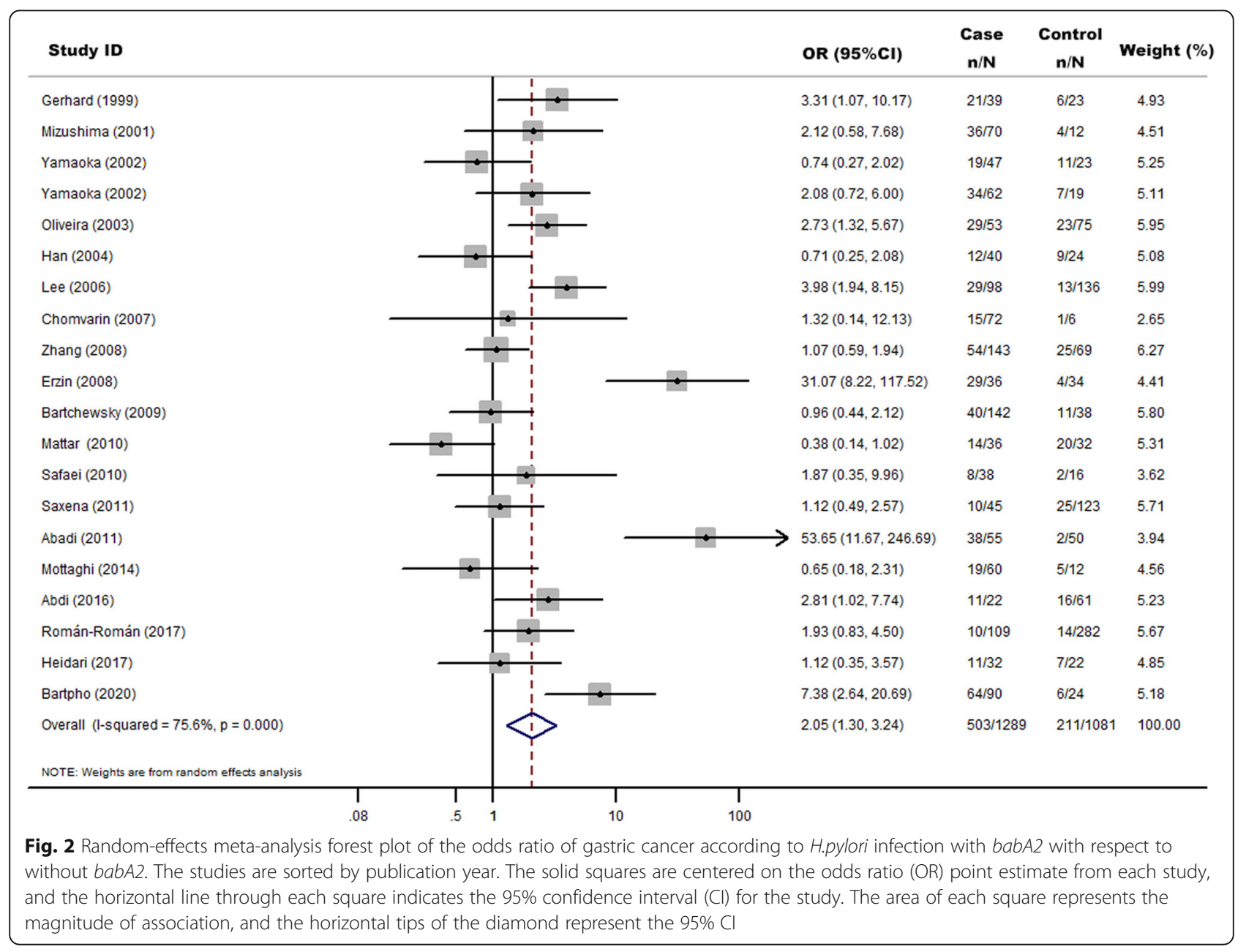




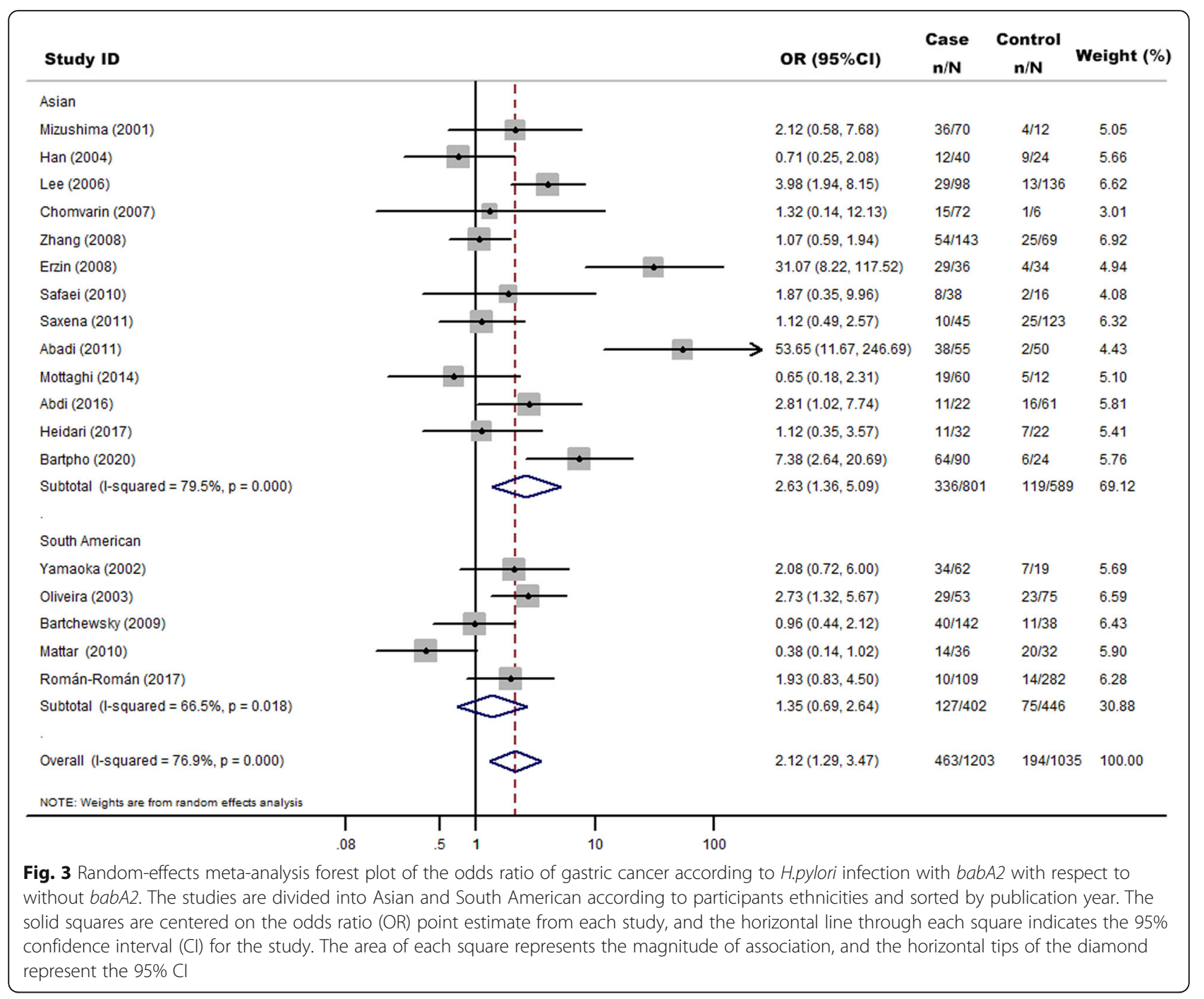

was no significant evidence of asymmetry distribution. And no significant publication bias was observed based on Begg's test $(P=0.284)$ or Egger's test $(P=0.288)$ (Figure S2). The impact of each study on the pooled OR was examined by repeating the meta-analysis while excluding individual study, which confirmed the stability of our results (Figure S3).

\section{Discussion}

To date, numerous studies have assessed the association between $H$. pylori babA2 gene and GC risk, but results remained inconsistent. The controversial results of individual studies may be due to relatively small sample size. Meta-analysis is an important approach to pool multiple studies and therefore may result in more precise and robust conclusion. In this meta-analysis, we included 20 studies focusing on $H$. pylori babA2 gene and GC risk with a total of 1289 patients and 1081 controls. We found that $H$. pylori babA2 gene was significantly associated with risk of GC. There is evidence that $H$. pylori increase the risk of GC development through the sequence of atrophy and metaplasia originate from several studies. Chronic $H$. pylori induced inflammation which can probably lead to loss of normal gastric mucosal, with gastric gland destruction, and replacement by fibrosis [53]. The $H$. pylori strains virulence factors, host and environmental factors are main factors to contribute in clinical infection manifestations [54]. And it is well showed that gene encoding pathogenic $H$ pylori factors are involved in GC development and colonization properties [29, 49].

The increased GC risk was also associated with coexpression of $H$ pylori vacAs1, cagA and babA2 genes $[17,18,23,55]$. Furthermore, interaction between host's immunological defenses and $H$ pylori virulence factors may play an important role in the development of GC 
[56, 57]. It was showed that $b a b \mathrm{~A} 2$ as a virulence marker could predict clinical outcome, which was dependent on the geographic origin of the $H$. pylori strains [27].

In our study, sub-group analysis according to geographical areas showed that $H$. pylori babA2 was not significantly associated with the risk of GC among South American. Our results are comparable to previous studies from South America [19, 26, 32, 34, 50]. The difference among populations may be due to the small sample size for each population, heterogeneity between studies and geographical factors. In other hand, H. pylori babA2 gene was closely involved in the risk of GC in Asian population, which was confirmed by original studies from Asian population [29, 30, 36, 38].

Our meta-analysis showed some limitations. Firstly, we didn't obtain original data, which have limited further evaluation of potential gene-gene and gene-environmental interactions. Secondly, the sample sizes of most included studies are relative small. Thirdly, additional analysis based on other factors, such as age, gender, family history, other virulence factors, environment factors (e.g. alcohol intake, smoking, high BMI) and GC subtypes (e.g. intestinal, diffuse or mixed type), could not be analyzed because of the limited information obtained from included studies. Finally, high heterogeneity among studies indicates that the pooled estimation risk should be interpreted with caution.

\section{Conclusions}

Our results suggest that the presence of $H$. pylori with positive $b a b A 2$ gene may contribute to increased risk of GC, especially in Asian population. Studies with large sample size are necessary to further elucidate the interaction among environmental factors, bacterial genotype and host factors on GC risk.

\section{Supplementary information}

Supplementary information accompanies this paper at https://doi.org/10. 1186/s12885-020-06962-7.

Additional file 1: Figure S1. Sub-group analysis of the association between $\mathrm{H}$. pylori babA2 gene and gastric cancer risk according to study quality assessment. Figure S2. Funnel plot of case-control studies evaluating the association between $\mathrm{H}$. pylori babA2 gene and gastric cancer risk. Each point represents a study to indicate an association. Figure S3. Influence of the summary OR coefficients on the association between $\mathrm{H}$. pylori babA2 gene and gastric cancer risk.

\footnotetext{
Abbreviations

babA: Blood-group antigen-binding adhesion; BMl: Body mass index; Cl: Confidence interval; GC: Gastric cancer; H. pylori: Helicobacter pylori; NOS: Newcastle-Ottawa Scale; OR: Odds ratio
}

Acknowledgements

Not applicable.

\section{Authors' contributions}

GJ and MAK conceived and designed the study. MAK extracted and analyzed data, interpreted results, and drafted the manuscript. MAK, JW and TW selected and assessed quality of studies. All authors reviewed the manuscript and approved the submitted version.

\section{Funding}

The authors declare that they did not receive funding for this research from any source.

\section{Availability of data and materials}

The datasets used and/or analysed during the current study are available from the corresponding author on reasonable request.

Ethics approval and consent to participate

Not applicable.

Consent for publication

Not applicable.

\section{Competing interests}

The authors declare that they have no conflicts of interests.

Received: 7 October 2019 Accepted: 13 May 2020

Published online: 24 May 2020

\section{References}

1. Bray $F$, et al. Global estimates of cancer prevalence for 27 sites in the adult population in 2008. Int J Cancer. 2013;132(5):1133-45.

2. Bertuccio $P$, et al. Recent patterns in gastric cancer: a global overview. Int J Cancer. 2009;125(3):666-73

3. Sigon R, Canzonieri V, Rossi C. Early gastric cancer: a single-institution experience on 60 cases. Suppl Tumori. 2003;2(5):S23-6.

4. Chen W, et al. Cancer statistics in China, 2015. CA Cancer J Clin. 2016;66(2): 115-32.

5. Ferlay J, et al. Cancer incidence and mortality worldwide: sources, methods and major patterns in GLOBOCAN 2012. Int J Cancer. 2015;136(5):E359-86.

6. World Cancer Research Fund International. Diet, nutrition, physical activity and stomach cancer. https://www.wcrf.org/sites/default/files/StomachCancer-2016-Report.pdf. Accessed 24 Dec 2019.

7. Cheng XJ, Lin JC, Tu SP. Etiology and prevention of gastric cancer. Gastrointest Tumors. 2016;3(1):25-36.

8. Correa P, Piazuelo MB. Helicobacter pylori infection and gastric adenocarcinoma. US Gastroenterol Hepatol Rev. 2011;7(1):59-64.

9. Wroblewski LE, Peek RM, Wilson KT. Helicobacter pylori and gastric cancer: factors that modulate disease risk. Clin Microbiol Rev. 2010;23(4):713-39.

10. Polk DB, Peek RM. Helicobacter pylori: gastric cancer and beyond. Nat Rev Cancer. 2010;10(6):403-14.

11. IARC Working Group on the Evaluation of Carcinogenic Risks to Humans. Schistosomes, liver flukes and helicobacter pylori. Lyon, 7-14 June 1994 IARC Monogr Eval Carcinog Risks Hum. 1994;61:1-241.

12. Shiota $\mathrm{S}$, et al. Systematic review and meta-analysis: the relationship between the helicobacter pylori dupA gene and clinical outcomes. Gut Pathog. 2010;2(1):13.

13. Costa AC, Figueiredo C, Touati E. Pathogenesis of helicobacter pylori infection. Helicobacter. 2009;14(Suppl 1):15-20.

14. Queiroz DM, et al. Factors associated with helicobacter pylori infection by a cagA-positive strain in children. J Infect Dis. 2000;181(2):626-30.

15. Blaser MJ, et al. Infection with helicobacter pylori strains possessing cagA is associated with an increased risk of developing adenocarcinoma of the stomach. Cancer Res. 1995;55(10):2111-5.

16. Atherton JC, et al. Mosaicism in vacuolating cytotoxin alleles of helicobacter pylori. Association of specific vacA types with cytotoxin production and peptic ulceration. J Biol Chem. 1995;270(30):17771-7.

17. Zambon CF, et al. Helicobacter pylori virulence genes and host IL-1RN and IL-1 beta genes interplay in favouring the development of peptic ulcer and intestinal metaplasia. Cytokine. 2002;18(5):242-51.

18. Yamaoka Y, et al. Relationship between helicobacter pylori iceA, cagA, and vacA status and clinical outcome: studies in four different countries. J Clin Microbiol. 1999:37(7):2274-9. 
19. Yamaoka Y, et al. Importance of helicobacter pylori oipA in clinical presentation, gastric inflammation, and mucosal interleukin 8 production. Gastroenterology. 2002;123(2):414-24.

20. Su YL, et al. Combination of OipA, BabA, and SabA as candidate biomarkers for predicting helicobacter pylori-related gastric cancer. Sci Rep. 2016;6: 36442.

21. Souod N, et al. The study of the oipA and dupA genes in helicobacter pylori strains and their relationship with different gastroduodenal diseases. Gastroenterol Hepatol Bed Bench. 2015;8(Suppl 1):S47-53.

22. Liu J, et al. Association of presence/absence and on/off patterns of helicobacter pylori oipA gene with peptic ulcer disease and gastric cancer risks: a meta-analysis. BMC Infect Dis. 2013;13:555.

23. Ilver $\mathrm{D}$, et al. Helicobacter pylori adhesin binding fucosylated histo-blood group antigens revealed by retagging. Science. 1998;279(5349):373-7.

24. Boren T, et al. Attachment of helicobacter pylori to human gastric epithelium mediated by blood group antigens. Science. 1993;262(5141): 1892-5.

25. Bartpho TS, et al. Precancerous gastric lesions with helicobacter pylori vacA $(+) /$ babA2(+)/oipA (+) genotype increase the risk of gastric cancer. Biomed Res Int. 2020;2020:7243029

26. Roman-Roman A, et al. Helicobacter pylori vacA s1m1 genotype but not cagA or babA2 increase the risk of ulcer and gastric cancer in patients from southern Mexico. Gut Pathog. 2017:9:18.

27. Heidari $\mathrm{K}$, et al. The prevalence of helicobacter pylori virulence related genes (hpa and babA2) in Iranian patients with gastrointestinal disorders. Jundishapur J Microbiol. 2017;10(12):e60947.

28. Mottaghi $B$, et al. Helicobacter pylori vacA i region polymorphism but not babA2 status associated to gastric cancer risk in northwestern Iran. Clin Exp Med. 2016;16(1):57-63.

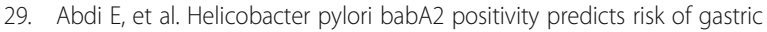
cancer in Ardabil, a very high-risk area in Iran. Asian Pac J Cancer Prev. 2016; 17(2):733-8.

30. Talebi Bezmin Abadi A, et al. High correlation of babA 2-positive strains of helicobacter pylori with the presence of gastric cancer. Intern Emerg Med. 2013;8(6):497-501.

31. Saxena A, et al. Virulence attributes of helicobacter pylori isolates \& their association with gastroduodenal disease. Indian J Med Res. 2011; 133:514-20.

32. Mattar R, et al. Association of LEC and tnpA helicobacter pylori genes with gastric cancer in a Brazilian population. Infect Agent Cancer. 2010;5:1.

33. Ghasemian Safaei H, et al. Relation of bab A2 genotype of helicobacter pylori infection with chronic active gastritis, duodenal ulcer and non-cardia active gastritis in Alzahra hospital Isfahan, Iran. Jundishapur J Microbiol. 2010:3(3):93-8.

34. Bartchewsky W Jr, et al. Effect of helicobacter pylori infection on IL-8, IL1 beta and COX-2 expression in patients with chronic gastritis and gastric cancer. Scand J Gastroenterol. 2009;44(2):153-61.

35. Zhang Z, et al. The helicobacter pylori duodenal ulcer promoting gene, dupA in China. BMC Gastroenterol. 2008:8:49.

36. Erzin $Y$, et al. Role of host interleukin 1beta gene (IL-1B) and interleukin 1 receptor antagonist gene (IL-1RN) polymorphisms in clinical outcomes in helicobacter pylori-positive Turkish patients with dyspepsia. J Gastroenterol. 2008:43(9):705-10.

37. Chomvarin C, et al. Prevalence of helicobacter pylori vacA, cagA, cagE, iceA and babA2 genotypes in Thai dyspeptic patients. Int J Infect Dis. 2008;12(1): 30-6.

38. Lee HS, et al. Expression of Lewis antigens and their precursors in gastric mucosa: relationship with helicobacter pylori infection and gastric carcinogenesis. J Pathol. 2006;209(1):88-94.

39. Han $\mathrm{YH}$, et al. Clinical relevance of iceA and babA2 genotypes of helicobacter pylori in a Shanghai population. Chin J Dig Dis. 2004;5(4):181-5.

40. Oliveira $A G$, et al. babA2- and cagA-positive helicobacter pylori strains are associated with duodenal ulcer and gastric carcinoma in Brazil. J Clin Microbiol. 2003:41(8):3964-6.

41. Mizushima T, et al. Clinical relevance of the babA2 genotype of helicobacter pylori in Japanese clinical isolates. J Clin Microbiol. 2001;39(7):2463-5.

42. Gerhard M, et al. Clinical relevance of the helicobacter pylori gene for blood-group antigen-binding adhesin. Proc Natl Acad Sci U S A. 1999; 96(22):12778-83.

43. Wells $\mathrm{G}$, et al. The Newcastle-Ottawa Scale (NOS) for assessing the quality of case-control studies in meta-analyses, vol. 25; 2011. p. 603-5.
44. Higgins JP, Thompson SG. Quantifying heterogeneity in a meta-analysis Stat Med. 2002;21(11):1539-58.

45. Cochran WG. The combination of estimates from different experiments. Biometrics. 1954:10(1):101-29.

46. DerSimonian R, Laird N. Meta-analysis in clinical trials. Control Clin Trials. 1986;7(3):177-88.

47. Egger $\mathrm{M}$, et al. Bias in meta-analysis detected by a simple, graphical test BMJ. 1997;315(7109):629-34.

48. Pormohammad A, et al. Risk of gastric cancer in association with helicobacter pylori different virulence factors: a systematic review and metaanalysis. Microb Pathog. 2018;118:214-9.

49. Chen MY, et al. Association of Helicobacter pylori babA2 with peptic ulcer disease and gastric cancer. World J Gastroenterol. 2013;19(26):4242-51.

50. Con SA, et al. Role of bacterial and genetic factors in gastric cancer in Costa Rica. World J Gastroenterol. 2009;15(2):211-8.

51. Zagari RM, Bazzoli F. Gastric cancer: who is at risk? Dig Dis. 2004;22(4):302-5.

52. Maeda S, et al. Relationship between nuclear factor-kappaB activation and virulence factors of helicobacter pylori in Japanese clinical isolates. $J$ Gastroenterol Hepatol. 2002;17(5):556-62.

53. Kuipers EJ, et al. Long-term sequelae of helicobacter pylori gastritis. Lancet. 1995;345(8964):1525-8.

54. Dhar SK, et al. Molecular mechanism of action of major helicobacter pylori virulence factors. Mol Cell Biochem. 2003;253(1-2):207-15.

55. Zambon CF, et al. Helicobacter pylori babA2, cagA, and s1 vacA genes work synergistically in causing intestinal metaplasia. J Clin Pathol. 2003; 56(4):287-91.

56. Marshall DG, et al. Genomic DNA fingerprinting of clinical isolates of helicobacter pylori using short oligonucleotide probes containing repetitive sequences. J Appl Bacteriol. 1996;81(5):509-17.

57. Akopyanz $\mathrm{N}$, et al. DNA diversity among clinical isolates of helicobacter pylori detected by PCR-based RAPD fingerprinting. Nucleic Acids Res. 1992; 20(19):5137-42.

\section{Publisher's Note}

Springer Nature remains neutral with regard to jurisdictional claims in published maps and institutional affiliations.
Ready to submit your research? Choose BMC and benefit from:

- fast, convenient online submission

- thorough peer review by experienced researchers in your field

- rapid publication on acceptance

- support for research data, including large and complex data types

- gold Open Access which fosters wider collaboration and increased citations

- maximum visibility for your research: over $100 \mathrm{M}$ website views per year

At BMC, research is always in progress.

Learn more biomedcentral.com/submissions 